\title{
The Relationship Between Cognitive Development and Language Learning in a Cross-Cultural Context: A Review of the Literature and its Implications
}

\section{Une Recension des ecrits Sur le Rapport Entre le Développement Cognitif et l'Apprentissage de la Langue en Contexte Interculturel}

\author{
Thinan Sangpanasthada \\ Brock University
}

\begin{abstract}
This article examines the relation of cognitive and language development in early childhood and their subsequent effects on individual cultural development. Then the influences of cultural difference on adult language learners (including ESL learners) are discussed in the hope that language instructors will gain a deeper appreciation of the difficulties that ESL learners encounter in the language learning process. While all language learners learn differently from each other, those from a given culture have certain characteristics in common that set them apart from learners with a different cultural background. This insight can assist language instructors in creating a teaching and learning environment that meets the learning needs of all their learners.
\end{abstract}

\section{Résumé}

Cet article explore la relation entre le développement de la cognition et de la langue chez le jeune enfant et les effets sur son

Thinan Sangpanasthada is a PhD candidate at Brock University, conducting research in adult second language learning. 
Thinan Sangpanasthada

développement culturel subséquent. Nous examinons l'influence de la difference culturelle sur l'adulte en situation d'apprentissage, en particulier l'adulte qui apprend l'anglais. Les resultats risquent d'intéresser les personnes qui enseignent l'anglais comme langue seconde, en leur fournissant une meilleure comprehension des difficultés que vivent les apprenantes et apprenants adultes. Au-delà des differences entre individus qui apprennent une langue seconde, nous présentons certaines caractéristiques propres aux personnes d'une culture particulière. Armés d'une comprehension de ces caractéristiques, les formatrices et formateurs peuvent créer des environnements plus propices à l'apprentissage adulte.

Researchers have long attempted to identify the factors that influence individual success in learning a new language. Following decades of investigation, a long list of factors has been compiled, and a consensus has emerged that places the individual's culture at or near the top of the list (e.g., Ashworth, 1992; Bell, 1988; Bloch \& Swadener1992; Brown, 1980; Cook, 1988; Dunn \& Griggs, 1995; Durkin, 1995; Ellis, 1985; Hahn, 1989; Jordan, Tharp \& Baird-Vogt, 1992; Lafayette \& Schulz, 1976; Mauranen, 1993; Ogbu, 1987; Paivio \& Begg, 1981; Reder, 1992; Reid, 1998; Saracho, 1993; Steffensen \& Joag-Dev, 1984)

However, most of the research in this area has so far considered culture only in its most general sense, and this has prevented a detailed, in-depth analysis of the specific ways in which culture affects second language acquisition. The literature makes almost no reference at all to the implications that the relationship between culture and language acquisition has for second language instruction. Clearly, further research is needed to determine the specific cultural differences that act as barriers for second language learners in the language learning process, and more work needs to be done to identify the strategies that second language instructors can use to minimize the effect of these cultural differences and thus facilitate second language acquisition.

In view of this need, this research paper will present: 1) an overview of language acquisition in terms of cognitive development; 2) a review of the cultural factors that influence second language 
acquisition as described in the literature; 3) specific cultural differences that impede some English as a Second Language (ESL) learners; and 4) implications for second language instruction that emerge from an analysis of the relationship between culture, cognitive development, and second language acquisition.

\section{Language acquisition and cognitive development}

Matlin (1989) has observed that "[t]he use of language is ... the one ability that most differentiates humans from other animals." Humans acquire language naturally and use it for a variety of purposes, including communication, self-expression, and information storage and transmission. For purposes of contrast, the following brief overview of language acquisition in terms of cognitive development is presented as a general background on the processes that come into play when humans acquire language naturally. The focus here will be limited to the period of infancy and early childhood, since this is the stage at which humans under normal circumstances acquire language naturally (as opposed to acquiring a second language, which generally takes place later in life).

Based on the work of Matlin (1989), the following points can be made in regard to the acquisition of language in infancy and early childhood in terms of the child's cognitive development:

- Studies on infants reveal that they are able to differentiate between highly similar sounds, that they are aware that a speaker's lips match the speech sounds coming from the speaker, and that they recognize the correspondence between tone of voice and facial expression.

- In the pre-verbal stage of language acquisition, young infants coo, and older infants babble. These vocalizations appear to have a communicative function, though the precise nature of this function has yet to be determined, and the communication may well be non-intentional. However, intentional communication does occur at this stage in the form of pointing and turn-taking.

- When language acquisition moves into the verbal stage, 
Thinan Sangpanasthada

the first words that children acquire are those that name objects, since objects are the items in the child's environment that are the most readily perceptible to the child's emerging cognitive functions.

- Children show overextension and underextensions in their word usage as their perception of word meaning changes from an emphasis on characteristic features to an emphasis on defining features.

- Despite the fact that they are telegraphic and omit words that have a purely grammatical function, the two-word utterances common among children in the next stage of cognitive development have the capacity to express a wide variety of complex relationships. This indicates that while linguistic development lags behind cognitive development, effective communication is already achievable.

- While language comprehension precedes and outstrips language output, children grow increasingly skilled in monitoring their language output and correcting their mistakes.

- Although young children frequently violate the unwritten rules of social behavior, they become aware at an early age of the importance of courtesy terms in social interactions. It is only as their cognitive development advances that they begin to follow more closely the rules that govern social interaction and cultural rituals. These rules are generally apprehended at a deep subconscious or unconscious level, and influence all future learning, including second language learning. (In the context of ESL learning, such rules often need to be consciously 'unlearned' if they are significantly different from those that govern the social uses of English.)

- At more advanced stages of cognitive development, children become aware of the interactive nature of communication. They begin to observe their listeners' responses and adapt their language output to these responses. They also become aware of their role as 
listeners and monitor their own responses to other speakers as they develop a sense of which responses are appropriate and which ones are not.

While most of the processes described above do not apply to second language learning, they establish patterns of cognition that may, later in life, interfere adversely with the acquisition of a second language. Contrasting the processes by which humans acquire language in infancy and early childhood with the language-learning processes of older learners and recognizing the potential that these differences have for interfering with later language learning provide important insights for ESL instruction.

\section{Second Language Learning}

Second language learning and aptitude vary considerably from individual to individual, and the level of proficiency achieved ranges widely from near-native fluency to bare minimum communicative competence. Some theorists note that second language learners who acquire the ability to use the language as proficiently as native speakers of the language are rare (Jahnke \& Nowaczyk, 1998). As Schneiderman \& Desmaris (1988) have pointed out, "to achieve native-like abilities in a second language, a person must master syntactic, semantic, and morphological knowledge, as well as [have] the talents for grammar and accent." To this list might be added the major cognitive shifts that are required of some second language learners, as noted above. This is a significant challenge for most adult learners, who often lack the time and motivation to put in the effort required to achieve such mastery. Thus, the most realistic goal of second language instruction would be communicative competence rather than native-like fluency. The significance of this claim will become apparent later on in this discussion, when specific cultural differences between the second-language learner and native-English speakers are examined.

\section{Definitions}

The use of English as a second language implies the acquisition 
Thinan Sangpanasthada

of English communication skills by non-native speakers. ESL acquisition is broadly defined as the internalization, by non-native speakers, of the rules and formulas that govern the use of English for the purposes of communicating in English (Ellis, 1985). According to some authorities, ESL training is defined as the providing of instruction in the use of English to non-native speakers in an English-speaking environment, that is, in a country such as Canada, the United States, or Britain (cf., TEFLNet - Network for TEFL teachers).

Culture is defined in various ways depending on the purpose for which the definition is being framed. However, for the purposes of examining the relation between culture and second language learning, a suitable working definition is one that views culture as "the distinctive body of customs, knowledge, beliefs, and morals, laws, habits, and social institutions that characterize each separate society" (Penn State University Affirmative Action Office, 2006). Cultural differences can thus be defined as those elements of any two or more given cultures that set those cultures apart to the extent that is possible to identify them clearly as two separate cultures.

\section{Overview of the influence of cultural differences in second language learning}

Much of the literature on the relationship between culture and second language learning is vague about the precise nature of the relationship and the specific role that culture plays in the process. However, the categorization of cultural differences suggested by Ogbu (1982) does provide a useful tool for the present analysis. In his scheme, there are three major types of cultural differences:

Universal cultural difference: For all learners, the transition from home to school involves adjusting to new behavioral requirements, social relations, style of language use or communication, and way of thinking.

Primary cultural difference: These are differences that existed before two culturally distinct populations came into contact with each other.

Secondary cultural differences: These arise after two 
cultures come into contact with each other, especially if one culture is more dominant than the other. Secondary cultural differences emerge as a reaction to this cultural domination. Their purpose is to protect the subordinate culture's own collective identity and to maintain a distinct boundary between the subordinate and the dominant culture.

From this analysis, it can be concluded that cultural differences play an important role in the second language learning process. ESL learners have to contend not just with universal cultural differences (such as those relating to the academic conventions of their new learning institution), but also with primary cultural difference and even the secondary cultural differences that arise as they struggle to preserve their cultural identity in their new surroundings (especially if they are learning English in an English-speaking environment). These various forms of cultural differences can interfere significantly with the learning process and slow down or even halt the learner's progress. Lack of progress can be the source of considerable discouragement psychologically to the ESL learner and can have an adverse effect on his or her motivation.

One of the primary cultural differences that relates specifically to second language learning is the difference in teaching and learning styles that exists between different cultures. According to Ashworth (1992), teaching and learning approaches can and do affect ESL learners. Teaching approaches and learning approaches differ greatly from culture to culture. Some learners may be confused and frustrated by the way their ESL instruction is delivered to them, particularly if they were brought up with and have become accustomed to a very different style of instruction delivery. In some cultures, for example, a teacher-centered approach may be preferred over a learner-centered approach. According to Prodromou (1991), a learner-centered approach has been favored by many language instructors because it promotes "autonomy of the learner, self-access work, guessing strategies, [and] a more systematic approach to grammar, and [it emphasizes] the importance of using the language for communication, attitude to the target culture, and so on." Like his Western counterparts, Prodromou (1991) reflects the commonly held view in the West that the learner-centered approach is more desirable for and 
more appropriate to second language learning than the teachercentered approach. However, the hierarchical nature of certain traditional cultures, particularly those in the East, does not permit the learner to be the focus of instruction or the dominant force in the classroom. A learner who has been raised in such a culture may have difficulty adjusting to an environment in which he or she is expected to participate actively in his or her own learning process.

While culture exerts a powerful influence on social and interpersonal interaction, as has been demonstrated above, it has an equally powerful effect on the individual's cognition, that is, the way he or she processes information, quite apart from the social or interpersonal interactions by which that information is acquired. Hahn (1989) notes that an important cognitive factor in the learning process is field independence vs. field dependence, that is, the extent to which a person differentiates or does not differentiate between specific details and the additional information that surrounds them. A fieldindependent person focuses almost exclusively on the details, and thus approaches situations analytically. A field-dependent person, on the other hand, sees the details primarily as part of the surroundings in which they are located, and thus takes a more global approach to interpreting the situation. Studies have shown that field-independent subjects have greater success in language learning situations in which the deductive method predominates, whereas field-dependent subjects perform better when the instruction is conducted through the use of examples. Because of their analytical approach, field-independent learners tend to perform better at language learning tasks that require them to apply rules, look for patterns, organize data, and make generalizations. Field-dependent learners, on the other hand, tend to learn more easily when their learning involves interaction with others (native speakers, in the case of ESL learners) in social situations. A similar study by Hansen \& Stansfield (1981) found that fieldindependent learners do better on tests of grammatical accuracy but do not perform as well in communicative tasks.

Hahn (1989) has found that cultures with more elaborate and rigid social structures, where the pressure to conform is great, tend to have individuals who are more field-dependent, while cultures in which individual freedom is stressed and technology is valued over human 
relationships produce individuals who are more field-independent. This finding suggests that individuals from Oriental cultures (which are rigidly and hierarchically structured) are more likely to be fielddependent, while those from Western cultures (which are more loosely structured and emphasize individuality) are more likely to be fieldindependent. It follows that native speakers of English are generally field-independent, and this might account for the difficulty that many Oriental ESL learners have in learning English from native speakers and eventually achieving near-native competence.

\section{Specific cultural differences that affect ESL learners}

\section{Values}

Attitudes to such matters as punctuality, privacy, and what society considers acceptable behavior in public may differ widely from one culture to the next. These attitudes inevitably affect the learner's behavior in the classroom. For example, a learner who comes from a culture that places a high value on privacy may have difficulty talking about himself or herself and his or her personal feelings in an ESL classroom for an activity organized by an ESL instructor who does not regard such discussions as an invasion of the learner's privacy.

\section{Age and Gender}

The relationship between younger and older individuals (or between children and adults) varies from culture to culture and this may interfere with the interaction between learner and instructor in the ESL classroom. For example, a learner may not disagree openly with an instructor simply as a mark of respect for an elder. A similar problem may arise in connection with the relationship between the genders. Female learners who come from certain traditional cultures may seem withdrawn and uncooperative in the ESL classroom, but may merely be following the social conventions of their culture, which 
Thinan Sangpanasthada

discourages women from speaking out in public. Male learners, likewise, may have problems, such as difficulty accepting instruction from a female instructor.

\section{Religion and Politics}

Religious beliefs often determine what is acceptable and unacceptable behavior, both in public and in private, and there are often religious taboos placed on certain subjects. For example, if a learner belongs to a religion that places a taboo on discussing sex in public, he or she will be extremely uncomfortable if an instructor introduces sex as a topic for discussion in a classroom activity. Such a learner may refuse to participate in the discussion or may even leave the room. Furthermore, if learners from two strongly opposed religions happen to be in the same classroom, tensions can arise between them that puts a strain on the learning process.

Political differences raise similar problems. Learners who come from opposite sides of a political conflict have been know to refuse to sit in the same classroom with each other or to break out into violent arguments with each other during classroom discussions. These incidents serve as distractions from the language learning process and consume the time and energy of both the learners and the instructor.

\section{Names}

In most cultures, an individual's name is integral to his or her identity. Thus, ESL learners appreciate it when their instructors make an effort to pronounce their names correctly. Anglicizing a name to make it easier to pronounce sends a subtle message to the learner that his or her identity is less important than the instructor's convenience. Worse still is the practice of giving learners "English" names, for it completely obliterates the learner's original identity. (English names may, of course, be given in some sort of role-playing or other activity with clearly defined boundaries, where it is clearly understood that the learner is being required to take on a different identity temporarily, for the purpose of the activity only). 
Cognitive development and language learning in a cross-cultural context

\section{Body language}

Body language differs greatly from culture to culture, and misunderstandings and embarrassment can result when gestures are misinterpreted. For example, in some cultures, looking down is a way of indicating respect or acknowledging one's subordinate status. However, in other cultures (including Western culture) downcast eyes are an expression of shame or an admission of guilt. Learners who look down when speaking to an instructor may create the wrong impression in the instructor's mind.

\section{Dress}

The manner in which a learner dresses may affect the learner's ability to interact properly with other learners. If a learner comes to class wearing the traditional costume of his or her culture, he or she may be subjected to ridicule from the other learners. Not only does this attack the learner's cultural identity, but it creates psychological problems that draw energy away from the learning process.

\section{Family expectations}

Family attitudes toward learning play an important part in the motivation and progress of language learners. Positive attitudes generally have a highly motivating influence on learners and generally produce positive outcomes (Ellis, 1985). However, excessively high expectations on the part of the family may lead to discouragement and loss of motivation on the part of the learner.

The following are some specific examples of how cultural differences can have a negative effect on an ESL learner's success in achieving communicative competence in English:

- Hierarchical societies, such as those in most Asian countries, require their members to respect age and social position, and this makes it difficult for younger individuals 
Thinan Sangpanasthada

or those in lower positions to challenge the views of their elders or superiors, even if these views are obviously wrong. ESL learners carry this socialization with them even when they move into an English-speaking environment or become part of a more egalitarian culture.

- In Thai and other Oriental cultures, criticism is often viewed as confrontational, and is therefore avoided. ESL learners who are not accustomed to giving or receiving criticism may feel uncomfortable when asked to engage in critical thinking and related activities, and this may limit their ability to complete the tasks. They do not want to judge or be judged, so they may not participate actively in such activities. There is a danger that this will be misinterpreted by the instructor as lack of interest or motivation, or sheer laziness.

- In some cultures, expressing one's opinions in public is considered immodest and self-promoting, and this attitude often inhibits ESL learners when they are required to participate in classroom discussions or interact with other learners. In some countries, the teaching approach is still somewhat teacher-centered: the instructor selects, presents, and assigns instructional materials (Reid, 1998). Speaking out in class is considered inappropriate for learners. The language learner is expected to play a highly passive role in the learning process.

- In some cultures, it is considered impolite to ask for clarification or further explanation, especially from an older person or superior, and ESL learners often remain silent, even when they do not understand what the instructor has said, for fear of offending him or her. In an environment where the instructor expects the learners to ask questions, the ESL learner from such a culture is at a distinct disadvantage.

- In some cultures, it is considered impolite to say 'No' to an older person or instructor. Thus, an ESL learner may answer 'Yes' when the instructor asks whether he or she has understood something, regardless of whether this is 
Cognitive development and language learning in a cross-cultural context

actually true or not. Naturally, the instructor takes the answer at face value and proceeds on the assumption that the learner has understood.

- In most Oriental cultures, it is considered rude for a younger person or a subordinate to make direct eye contact with an adult or a social superior. In Western culture, however, direct eye contact is expected of anyone who is interacting with another person, and reluctance or failure to establish eye contact is often interpreted as a sign of dishonesty or guilt, or, at the very least, as an indication of lack of openness. Thus, Oriental ESL learners are often misjudged or regarded with distrust by Western instructors.

\section{Implications for second language instruction}

The cultural differences described above have several implications for instruction in the ESL classroom. Insights gained from a discussion of these cultural differences can be used by language instructors as a guide in planning teaching activities that are appropriate to the learners they are dealing with. Below are some practical suggestions that ESL instructors can follow in developing their own cultural awareness and bridging the culture gap between them and their learners:

- Obtain as much background information as possible about learners through home language surveys and learners'

files. The more familiar the instructor is with the learners' cultural background, the more effective he or she will be in providing them with instruction that meets their needs in ways that they are comfortable with.

- Be careful not to use materials that have culturally biased content, that is, content that assumes that the learner already has knowledge of certain facts that are specific to a given culture. Learners from non-Christian cultures may have little knowledge of the traditions associated with Easter, for example. 
Thinan Sangpanasthada

- $\quad$ Be prepared to provide sufficient advanced organizers (organizational materials) to aid in comprehension.

Language learners need input in a variety of ways such as charts, outlines, and visuals so that they can make the best possible connections with prior knowledge.

- $\quad$ Keep the cultural backgrounds of the learners in mind when assigning them to groups for group activities. A mismatch of cultures among learners in a group has the potential for creating serious problems between individual group members. If a poor match is unavoidable, monitor the interaction of the group members to make sure that culture does not get in the way of the interaction and the learning that is expected to take place.

- Develop a program that helps learners to respect each other and to work together in uplifting their culture and community. This is a useful baseline teaching strategy. If a learner's culture is valued and understood by his or her instructor and fellow learners as well as by the larger community, he or she will do better in the classroom than the learner who feels that his or her culture is ignored or denigrated.

- Monitor the learners' progress frequently by checking for learning and understanding, and use several different methods of assessment. The greater the frequency and diversity of a learner's assessment, the greater the opportunity he or she will have to demonstrate that learning has taken place.

Be aware that the external or home environment can be either a help or an impediment to learning. Learning will be effective only if families and neighbors are included in the learning process. Focus on the strengths of the learners, their families, and the environments in which they live.

Above all, do not expect learners to achieve native-like proficiency in English, since they will have to make the difficult leap across the culture barrier to do so. A more realistic goal is communicative competence; that is, the learners are able to communicate clearly in English what they intend to communicate while 
at the same time retaining the "flavor" of their original culture (accent, inflection, body language, mannerisms, way of thinking, etc.) in their communicative discourse.

\section{Conclusion}

This paper has examined the effect that cultural differences have on language learners (including ESL learners) in the hope that language instructors will gain a deeper appreciation of the difficulties that ESL learners encounter in the language learning process. While all language learners learn differently from each other, those from a given culture have certain characteristics in common that set them apart from learners with a different cultural background. This insight can assist language instructors in creating a teaching and learning environment that meets the learning needs of all their learners, regardless of where each individual learner comes from. There are many complex dimensions to cultural differences, and these are often difficult for language instructors and language learners to understand. However, these difficulties need to be overcome if successful pedagogical outcomes are to be achieved.

\section{References}

Ashworth, M. (1992). The first step on the longer path: Becoming an ESL teacher. CANADA: Pippin Publishing Limited.

Bell, J. (1988). Teaching Multilevel Classes in ESL. CANADA: Doinie Press Limited.

Bloch, M. \& Swadener, B. (1992). Relationship Between Home, Community and School: Multicultural Considerations and Research Issues in Early Childhood. In C.A.Grant (Ed.), Research \& Multicultural Education (pp. 165-183).

London:The Falmer Press.

Brown, H. (1980). The Optimal Distance Model of Second Language Acquisition. N.J.: Prentice-Hall. 
Thinan Sangpanasthada

Cooke, D. (1988). Language with Strings Attached. In E. V.C. Harris \& H.M. McGarrell (Eds.), TESL'88. (pp. 27-35).

Dunn, R. \& Griggs, S.A. (1995). Multiculturalism and Learning Styles: Teaching and Counseling Adolescents. US. Praeger Publishers.

Durkin, D. (1995). Language Issues: Reading for Teachers. New York: Longman.

Ellis, R. (1985). Understanding Second Language Acquisition. Oxford: Oxford University Press.

Hahn, C. (1989). Dealing with Variable in the language Classroom. In T. Kral (Ed.) (1994), Teacher Development: Making the Right Moves (pp. 76-82). Washington, DC: English Language Program Division, United States Information Agency.

Jahnke, J.C. \& Norwaczyk, R.H. (1998). Cognition. N.J: PrenticeHall, Inc.

Jordan, C., Tharp, R.G. \& Baird-Vogt, L. (1992). "Just Open the Door". Cultural Compatibility and Classroom Rapport. In M. Saravia-Shore \& S. F. Arvizu (Eds.), Cross-Cultural Literacy: Ethnographies of Communication in Multiethnic Classrooms (pp. 3-18). US: Garland Publishing, Inc.

Lafayette, R.C. \& R. Schulz. (1976). Evaluation Cultural Learning. In R.C. Lafayette (Ed.), The Culture Revolution in Foreign Language Teaching (pp. 104-118). IL: National Textbook Company.

Matlin, M.W. (1989). Cognition. US: Holt, Rinehart and Winston, Inc.

Mauranen, A. (1993). Cultural Differences in Academic Rhetoric. Germany: Peter Lang.

Ogbu, J. U. (1987). Opportunity Structure, Cultural Boundaries, and Literacy. In J. A. Langer (Ed.), Language, Literacy, and Culture: Issues of Society and Schooling. NJ: Ablex Publishing Corporation.

Paivio, A. \& Begg, I. (1981). Psychology of Language. NJ: Prentice-Hall, Inc.

Prodromor, L. (1991). The Good Language Teacher. In T. Kral (Ed.) (1994), Teacher Development: Making the Right Moves 
(pp. 18-33). Washington, D.C.: English Language Program Division, United States Information Agency.

Reder, S. (1992). Getting the Message Across: Cultural Factors in the Intergenerational Transfer of Cognitive Skills. In . G. Sticht, M. J. Beerler \& B. A. McDonald (Eds.), The Intergenerational Transfer of Cognitive Skills (pp. 202-228). NJ: Ablex Publishing Corporation.

Reid, J.M. (Ed). (1998). Understanding Learning Styles in the Second Language Classroom. NJ: Prentice-Hall, Inc.

Saracho, O.N. (1993). Cultural Differenced in the Cognitive Style of Mexican-American Students. In B. J. Robinson Shade (Ed.), Culture, Style, and the Educative Process: Making Schools Wok for Racially Diverse Students ( $p p$. 118125).I.L.: Charles C Thomas Publishing, Ltd.

Schneiderman, E.I. \& Desmaris, C. (1988). A Neuropsychological substrate for talent in second-language acquisition. In L.K. Obler \& D. Fein (Eds.), The Exceptional Brain: Neuropsychology of talent and special abilities. NY: Guilford Press.

Steffensen, M. \& Joag-Dev, C. (1984). Cultural knowledge and reading. In Alderson, $J$. \& Urquhart, A. H. (Eds.), Reading in a Foreign Language (pp. 48-64). Singapore: Selector Printing Co (Pte), Ltd.

Penn State University Affirmative Action Office (2006). Policies, Statements, and Definitions. Retrieved May 17, 2006, from: http://www.psu.edu/dept/aaoffice/definitions.htm.

TEFLNet - Network for TEFL Teachers. Retrieved on May 17, 2006, from: www.tefl.net/faq.htm. 